\title{
Association of Serum Osteocalcin and Neutrophil-Lymphocyte Ratio with Bone Mineral Density for the Diagnosis of Osteoporosis
}

Syeda Zannatul Ferdaus Udita ${ }^{1}$, Sheuly Ferdousi ${ }^{2}$, Tanveer Ahmed Chowdhury ${ }^{3}$, Mst Shaila Yasmin ${ }^{4}$, Maliha Kamal ${ }^{5}$, Saifun Nahar ${ }^{6}$, Kazi ShamimUzzaman ${ }^{7}$, Mesbah Uddin Ahmed ${ }^{8 *}$, Debataus Paul', Md. Quddusur Rahman ${ }^{10}$, Md. Saiful Islam²

${ }^{1}$ Clinical Pathologist, National Institute of Cardiovascular Diseases, Dhaka.

${ }^{2}$ Associate Professor, Department of Laboratory Medicine, Bangabandhu Sheikh Mujib Medical University.

${ }^{3}$ Resident Medical Officer, National Institute of Diseases of the Chest and Hospital, Dhaka.

${ }^{4}$ Assistant Professor, Department of Laboratory Medicine, Bangabandhu Sheikh Mujib Medical University.

${ }^{5}$ Medical Officer, Directorate General of Health Services, Dhaka.

${ }^{6} \mathrm{MD}$ (Laboratory Medicine), Bangabandhu Sheikh Mujib Medical University.

${ }^{7}$ Professor, Ortho-surgery, National Institute of Traumatology and Orthopedic Rehabilitation

${ }^{8} \mathrm{MS}$ in Microbiology, Bangladesh University of Health Sciences.

${ }^{9}$ Professor and Chairman, Department of Laboratory Medicine, Bangabandhu Sheikh Mujib Medical University.

${ }^{10}$ Professor and Ex-Chairman, Department of Laboratory Medicine, Bangabandhu Sheikh Mujib Medical University.

*Corresponding Author: Mesbah Uddin Ahmed, MS in Microbiology, Bangladesh University of Health Sciences.

\section{Received Date: 26 August 2021 | Accepted Date: 11 September 2021 | Published Date: 18 September 2021}

Citation: S Z F Udita, S Ferdousi, Tanveer A Chowdhury, Mst S Yasmin, Mesbah U Ahmed. et al.(2021) Association of Serum Osteocalcin and Neutrophil-Lymphocyte Ratio with Bone Mineral Density for the Diagnosis of Osteoporosis. Journal of Clinical and Laboratory Research. 3(4); DOI:10.31579/2768-0487/045

Copyright: (C) 2021 Mesbah Uddin Ahmed. This is an open-access article distributed under the terms of the Creative Commons Attribution License, which permits unrestricted use, distribution, and reproduction in any medium, provided the original author and source are credited.

\section{Abstract}

Introduction: Osteoporosis is often under diagnosed, under treated and imposed a considerable economic burden on the health system. About two fifth of the post-menopausal women of Bangladesh are affected. Early diagnosis is necessary to halt the disease process. Serum osteocalcin, neutrophil-lymphocyte ratio (NLR) increases and bone mineral density (BMD) decreases in osteoporosis. There is no specific diagnostic test for osteoporosis except BMD. It is costly, has radiation hazard and not available in all laboratories in our country. On the other hand, serum osteocalcin and NLR are easily available and a promising marker which can be done as routine blood test for the diagnosis of osteoporosis.

Objective: The objective of the study was to evaluate the association of serum osteocalcin and NLR with BMD for the diagnosis of osteoporosis.

Materials and methods: This cross-sectional study was conducted in the Department of Laboratory Medicine and the Department of Orthopedic Surgery, Bangabandhu Sheikh Mujib Medical University (BSMMU) and Dhaka Medical College Hospital (DMCH) from March, 2020 to February, 2021. A total 50 diagnosed patient of osteoporosis, who fulfil the inclusion and exclusion criteria were selected as study population. They were grouped as normal, osteopenia and osteoporosis according to T-score of BMD report. Serum osteocalcin and NLR evaluated from routine blood test. Statistical analysis was done by statistical package for social science (SPSS) software windows version 22.

Results: Negative Pearson's correlation was found between serum osteocalcin with T-score of BMD $(r=-0.812, p=0.002)$ and between NLR with T-score of BMD ( $\mathrm{r}=-0.826, p=0.001)$. In receiver operating characteristic (ROC) curve analysis, cut off value of serum osteocalcin was $18.65 \mathrm{ng} / \mathrm{mL}$ having sensitivity $67.0 \%$ and specificity $70.0 \%$ with a cut off value of NLR was 4.54 with sensitivity $72.0 \%$ and specificity $75.0 \%$. 
Conclusion: Serum osteocalcin and NLR has significant negative correlation with T-score of BMD. Because of high sensitivity and specificity, serum osteocalcin and NLR may be used to diagnosis of osteoporosis

Keywords: bone mineral density; osteoporosis; osteopenia; t-score; osteocalcin; neutrophil-lymphocyte ratio

\section{Introduction}

Osteoporosis is a serious public health concern due to its important worldwide prevalence. Osteoporosis is underdiagnosed, undertreated and imposed a considerable economic burden on the health system [4]. During lifetime $30-50 \%$ of women and $15-30 \%$ of men are at risk to osteoporosis all over the world $[12,7]$. Currently it is estimated that, about 1.6 million hip fractures occur each year worldwide [8]. The incidence is increase to 6.3 million by 2050 . Among them more than $50 \%$ will occur in Asia [8]. In Bangladesh, $43.6 \%$ of 16-45 years old women and $40.70 \%$ of $46-65$ years old women had osteopenia and $5.5 \%$ of $16-45$ old women and $41.80 \%$ of $46-65$ years old women had osteoporosis [1]. Its prevalence is increasing with menopause, vitamin D deficiency, low body weight, low intake of calcium, some diseases and use of some medications [8]. Therefore, it is necessary to find out an easy, reliable, cost effective marker for the diagnosis of osteoporosis. Serum osteocalcin is a single blood-based laboratory test for the diagnosis of osteoporosis with good sensitivity and specificity. It is an accessible, easily performed and has a better role for the diagnosis of osteoporosis. On the other hand, NLR is also a simple, cost effective, repeatable and less hazardous tool for the diagnosis of osteoporosis. It can be done in small setup with minimum laboratory facilities. Though BMD is the gold standard test for the diagnosis of osteoporosis, it has some limitations, like risk of radiation exposure, presence of metal may interfere the result of test, needs expertise, not available in routine hospital setup. In this study, we try to explore the role of serum osteocalcin and NLR in comparison with BMD for the diagnosis of osteoporosis.

\section{Materials and Methods}

Study design: Cross-sectional study

Study duration: March 2020 to February 2021

Place of study: The study was conducted in the Department of Laboratory Medicine and the Department of Orthopedic Surgery, BSMMU and DMCH, Dhaka.

Study population: All clinically suspected patients of osteoporosis from outpatient department (OPD) of Department of Orthopedic Surgery, BSMMU and DMCH was enrolled in to the study. Diagnosis of osteoporosis patient was conducted by history taking and measurement of BMD by DEXA scan.

\section{Patients Selection Criteria}

Inclusion criteria: Female over 45 years of age and Male over 50 years of age.

Exclusion criteria: Acute infection, Chronic infection, Malignancies, Diabetes mellitus, Acromegaly, Cushing's syndrome, Hyperparathyroidism, Liver disease, Renal disease, Intestinal malabsorption, Hormonal therapy, Use of some medications like antacids containing aluminum, anticonvulsant drugs, steroids, heparin, methotrexate, etc.

Sample size: As per inclusion criteria available diagnosed case of osteoporotic patients were enrolled in this study. Sample size was 89. Sample was collected 50 due to COVID-19 pandemic situation. Among them 8 were normal, 32 were osteopenic patients and 10 were osteoporotic patients.
Sampling technique: Purposive sampling was followed. As per selection criteria the patients are enrolled in this study. The whole procedure was explained to the participants and informed consent of both verbal and written was taken.

\section{Study procedure}

- After ethical clearance from Institutional Review Board (IRB), diagnosed case of osteoporosis according to BMD report, who were attended in OPD of Department of Orthopedic Surgery, BSMMU and $\mathrm{DMCH}$, was selected.

- After considering the inclusion and exclusion criteria the patient was included in this study and full explanation regarding the aims, objectives of the study and necessity of the investigation was informed.

- At first age and sex matched osteoporosis patients diagnosed by BMD reports was taken.

- Then blood sample of the patient was drawn for serum osteocalcin and NLR. It was done at the Department of Laboratory Medicine, BSMMU,

\section{Laboratory procedure}

\section{Blood sample collection}

Blood sample was collected from antecubital vein after aseptic precaution with $0.5 \%$ chlorhexidine gluconate. About $4.0 \mathrm{~mL}$ venous blood was taken into red tube $(2.0 \mathrm{~mL})$ and violet tube $(2.0 \mathrm{~mL})$. Tube was labeled with the patient's identification number and kept it for 30 minutes. Then blood was centrifuged $3000 \mathrm{rpm}$ for 5 minutes.

- For serum osteocalcin

Blood sample: $2 \mathrm{~mL}$.

Tube: Red screw capped plain tube without anticoagulant. Specimen: Serum.

\section{- For NLR}

Blood sample: $2 \mathrm{~mL}$.

Tube: Violet screw capped tube containing EDTA anticoagulant. Specimen: Whole blood.

\section{Test procedure}

- For estimation of serum osteocalcin

The serum osteocalcin level was assessed by Electrochemiluminescence Immunoassay (ECLIA) by COBAS immunoassay auto analyzer in the Department of Laboratory Medicine, BSMMU. Result of serum osteocalcin level was based on reference range. Test result was given within 15-20 minutes.

o Reference range of serum osteocalcin: In case of adult male, it is $5.8-14.0 \mathrm{ng} / \mathrm{mL}$ and in case of adult female it is $3.10-14.4$ $\mathrm{ng} / \mathrm{mL}(11)$.

o Grading of serum osteocalcin: In osteopenia it is $19.25 \pm 5.09$ $\mathrm{ng} / \mathrm{mL}$, in mild osteoporosis it is $21.34 \pm 3.9 \mathrm{ng} / \mathrm{mL}$ and in severe osteoporosis it is $22.9 \pm 4.9 \mathrm{ng} / \mathrm{mL}$ (Singh, Kumar \& Lal, 2015). 


\section{- For calculation of NLR}

O Neutrophil-lymphocyte differential count obtained from CBC report which was estimated by Hematology Autoanalyzer (Sysmex XN-2000) which again confirmed manually by peripheral blood smear.

O NLR was calculated from dividing the absolute neutrophil count by the absolute lymphocyte count.

O Range of NLR: Between 0.78 and 3.53 (Forget et al., 2017).

O NLR in osteopenia is $2.37 \pm 1.00$ and in osteoporosis is $2.54 \pm 1.45(10)$.

\begin{tabular}{|c|l|l|l|l|}
\hline & Normal & Osteopenia & Osteoporosis & p value \\
\hline Subjects & & & & \\
\hline Number & 8 & 32 & 10 & \\
\hline Percentage (\%) & 16.0 & 64.0 & 20.0 & \\
\hline T-score of femoral neck & & & & \\
\hline Mean \pm SD & $0.43 \pm 0.92$ & $-1.79 \pm 0.41$ & $-3.01 \pm 0.66$ & 0.001 \\
\hline Range(min,max) & $-1.6,1.7$ & $-2.3,-1.1$ & $-4.7,-2.6$ & \\
\hline
\end{tabular}

Normal (T score $\geq-1$ ), Osteopenia (T score $<-1$ and $>-2.5)$, Osteoporosis $(\mathrm{T}$ score $\leq-2.5$ ) $\mathrm{p}$ value reached from ANOVA test

\section{- For measurement of BMD}

O BMD measured by DEXA scan.

O BMD grading according to WHO on the basis of T-score (8).

- Normal BMD - T-score $\geq-1$

- Osteopenia - T-score $<-1$ and $>-2.5$

- Osteoporosis $-\mathrm{T}$-score $\leq-2.5$

\section{Results}

Table 1: Distribution of the study subjects by $T$-score of femoral neck $(n=50)$.
Distribution of the study subjects according to T-score of femoral neck observed that almost two third $(64.0 \%)$ subjects had osteopenia followed by $10(20.0 \%)$ osteoporosis and $8(16.0 \%)$ normal.The mean $( \pm$ SD) T- score of femoral neck was $0.43 \pm 0.92$ in normal, $-1.79 \pm 0.41$ in osteopenia and $-3.01 \pm 0.66$ in osteoporosis. The difference was statistically significant ( $\mathrm{p}=0.001)$ among the subjects.

\begin{tabular}{|l|l|l|l|l|l|l|l|}
\hline Age (in years) & \multicolumn{2}{l|}{$\begin{array}{l}\text { Normal } \\
(\mathrm{n}=8)\end{array}$} & \multicolumn{2}{l|}{$\begin{array}{l}\text { Osteopenia } \\
(\mathrm{n}=32)\end{array}$} & \multicolumn{2}{l|}{$\begin{array}{l}\text { Osteoporosis } \\
(\mathrm{n}=10)\end{array}$} & $\mathrm{p}$ value \\
\hline & $\mathrm{n}$ & $\%$ & $\mathrm{n}$ & $\%$ & $\mathrm{n}$ & $\%$ & \\
\hline $40-50$ & 2 & 25.0 & 1 & 3.1 & 0 & 0.0 & \\
\hline $51-60$ & 2 & 25.0 & 17 & 53.2 & 6 & 60.0 & \\
\hline $61-70$ & 2 & 25.0 & 12 & 37.5 & 2 & 20.0 & \\
\hline $71-80$ & 2 & 25.0 & 2 & 6.2 & 2 & 20.0 & \\
\hline Mean \pm SD & $55.25 \pm 12.44$ & $63.06 \pm 6.46$ & $63.5 \pm 8.18$ & 0.044 \\
\hline Range (min,max) & 38,73 & 48,80 & 55,80 & & \\
\hline
\end{tabular}

$\mathrm{p}$ value reached from ANOVA test

Table 2: Distribution of the study subjects by age $(n=50)$.

In this current study, it was observed that most of the patient of osteopenia and osteoporosis were in 51-60 years age group. The mean $( \pm \mathrm{SD})$ age was $55.25 \pm 12.44$ years in normal, $63.06 \pm 6.46$ years in osteopenia and
$63.5 \pm 8.18$ years in osteoporosis. Differences of mean $( \pm \mathrm{SD})$ age among the subjects were statistically significant $(\mathrm{p}=0.044)$.

\begin{tabular}{|l|l|l|l|c|}
\hline Serum Osteocalcin & $\begin{array}{l}\text { Normal } \\
(\mathrm{n}=8)\end{array}$ & $\begin{array}{l}\text { Osteopenia } \\
(\mathrm{n}=32)\end{array}$ & $\begin{array}{l}\text { Osteoporosis } \\
(\mathrm{n}=10)\end{array}$ & $\mathrm{p}$ value \\
\hline Mean \pm SD & $13.88 \pm 1.11$ & $20.84 \pm 5.21$ & $24.32 \pm 5.24$ & 0.001 \\
\hline Range(min,max) & $11.3,14.4$ & $13.1,36.713$ & $12.6,32.1$ & \\
\hline
\end{tabular}

Table 3: Distribution of study subjects according to serum osteocalcin $(n=50)$.

Serum osteocalcin: In case of adult male, it is $5.8-14.0 \mathrm{ng} / \mathrm{mL}$ and in case of adult female it is $3.10-14.4 \mathrm{ng} / \mathrm{mL}$ (11). $\mathrm{p}$ value reached from ANOVA test
The mean $( \pm \mathrm{SD})$ serum osteocalcin was $13.88 \pm 1.11 \mathrm{ng} / \mathrm{mL}$ in normal, $20.84 \pm 5.21 \mathrm{ng} / \mathrm{mL}$ in osteopenia and $24.32 \pm 5.24 \mathrm{ng} / \mathrm{mL}$ in osteoporosis. The difference was statistically significant $(\mathrm{p}=0.001)$ among the subjects. 


\begin{tabular}{|l|l|l|l|c|}
\hline NLR & $\begin{array}{l}\text { Normal } \\
(\mathbf{n = 8})\end{array}$ & $\begin{array}{l}\text { Osteopenia } \\
(\mathbf{n}=\mathbf{3 2})\end{array}$ & $\begin{array}{l}\text { Osteoporosis } \\
(\mathbf{n = 1 0})\end{array}$ & p value \\
\hline Mean \pm SD & $3.11 \pm 2.8$ & $4.49 \pm 2.04$ & $6.35 \pm 2.2$ & 0.010 \\
\hline Range(min,max) & $1.1,3.53$ & $1.2,8.5$ & $2.4,10.9$ & \\
\hline
\end{tabular}

Table 4: Distribution of study subjects according to $N L R(n=50)$.

Reference range of NLR: 0.78-3.53 (Forget et al. 2017), p value reached from ANOVA test

The mean $( \pm$ SD) NLR was $3.11 \pm 2.8$ in normal, $4.49 \pm 2.04$ in osteopenia and $6.35 \pm 2.2$ in osteoporosis. The difference was statistically significant $(\mathrm{p}=0.010)$ among the subjects.

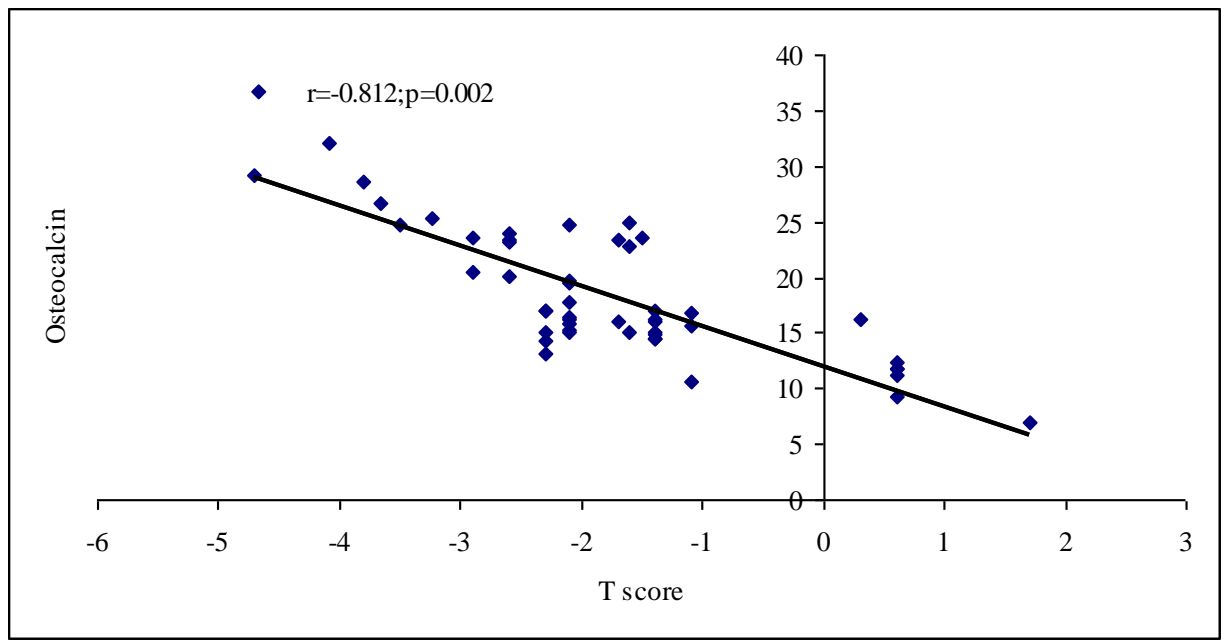

Figure 1: Scatter diagram showing Pearson's correlation between serum osteocalcin with T-score.

Figure 1 shows that there is a negative correlation between serum osteocalcin with T-score ( $\mathrm{r}=-0.812)$. It was observed that the Pearson's correlation statistically significant $(\mathrm{p}=0.002)$.

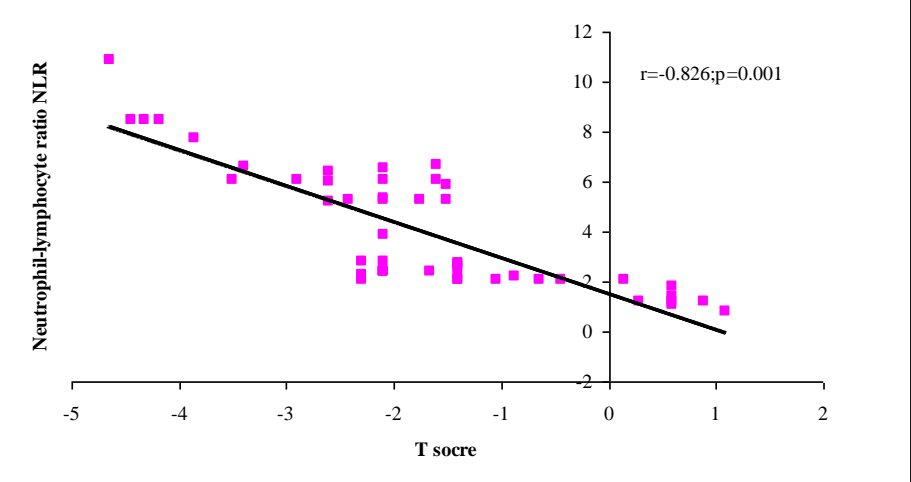

Figure 2: Scatter diagram showing Pearson's correlation between NLR with T-score

Figure 2 shows that there is a negative correlation between NLR with T-score ( $\mathrm{r}=-0.826)$. It was observed that the Pearson's correlation statistically significant $(\mathrm{p}=0.001)$.

\begin{tabular}{|l|l|l|l|l|l|l|l|}
\hline & & Sensitivity & Specificity & \multirow{2}{*}{$\begin{array}{c}\text { Area under } \\
\text { the ROC curve }\end{array}$} & & & \multicolumn{2}{|c|}{ 95\% Confidence interval (CI) } \\
\cline { 5 - 9 } & Cut off value & & & 0.547 & 0.585 & 0.351 & 0.742 \\
\hline Serum osteocalcin & 18.65 & 67.0 & 70.0 & 0.658 & 0.066 & 0.478 & 0.838 \\
\hline NLR & 4.54 & 72.0 & 75.0 & Upper bound \\
\hline
\end{tabular}

Table 5: ROC curve of serum osteocalcin and NLR for prediction of osteoporosis.

The area under the ROC curve of serum osteocalcin and NLR for prediction of osteoporosis is depicted in the above table. ROC curve was constructed using serum osteocalcin with a cut off value of $18.65 \mathrm{ng} / \mathrm{mL}$ having $67.0 \%$ sensitivity and $70.0 \%$ specificity for prediction of osteoporosis. Similarly, NLR had a best combination of sensitivity and specificity with a cut off value of 4.54 having $72.0 \%$ sensitivity and $75.0 \%$ specificity for prediction of osteoporosis. ROC curve shows, NLR 
having batter sensitivity $72.0 \%$ and specificity $75.0 \%$ than serum osteocalcin.

\section{Discussion}

Osteoporosis, a multifactorial process, is a bone metabolic disease. It is often under diagnosed, under treated and imposed a considerable economic burden on the health system. It is one of the important causes of morbidity in elderly population worldwide, including Bangladesh. So, early diagnosis is necessary to halt the disease process. There may be an association between serum osteocalcin, NLR and BMD for the diagnosis of osteoporosis. This cross-sectional study was carried out in the Department of Laboratory Medicine, BSMMU, Shahbag, Dhaka from the period of March 2020 to February 2021. A total of 50 patients with diagnosed case of osteoporosis from the Department of Orthopedic Surgery, BSMMU and DMCH were enrolled in to the study. According to $\mathrm{T}$-score of femoral neck patients were classified as normal (T-score $\geq$ 1 ), osteopenia (T-score <-1 and >-2.5) and osteoporosis (T-score $\leq-2.5$ ). The aim of this study was to evaluate the association between serum osteocalcin, NLR with BMD for the diagnosis of osteoporosis. In this present study, according to T-score of femoral neck it was observed that $16.0 \%$ subjects were normal, $64.0 \%$ were osteopenia and $20.0 \%$ were osteoporosis. We observed that the mean $( \pm \mathrm{SD})$ T-score of femoral neck was $0.43 \pm 0.92$ in normal group, $-1.79 \pm 0.41$ in osteopenia and $-3.01 \pm 0.66$ in osteoporosis. Chaudhary et al. (2019) found in their study that normal was $24.2 \%$, osteopenia was $38.5 \%$ and osteoporosis was $37.3 \%$. Singh, Kumar and Lal (2015) study observed that there were $39.0 \%$ cases had osteopenia and $61.0 \%$ cases had osteoporosis. Öztürk et al. (2013) study showed $38.2 \%$ patients with osteopenia, $53.6 \%$ patients with osteoporosis, and $8.2 \%$ were control subjects. These results are not consistent with our study. It may be due to small sample size or demographic variables. In this current study, we observed that the mean $( \pm \mathrm{SD})$ age was $55.25 \pm 12.44$ years in normal group, $63.06 \pm 6.46$ years in osteopenia and $63.5 \pm 8.18$ years in osteoporosis. Differences of mean $( \pm$ SD) age between the subjects was statistically significant. We also observed that, among the subject's incidence was more in between age 51-60 years. Singh, Kumar and Lal (2015) observed the mean $( \pm$ SD) age was $57.27 \pm 9.4$ years in case group and $51.76 \pm 10.7$ years in control group. Another study by Kalaiselvi et al. (2013) observed the mean $( \pm \mathrm{SD})$ age was $53.6 \pm 12.5$ years in osteoporotic subjects and $50.44 \pm 12.1$ years in non-osteoporotic subjects. The difference was statistically significant. These studies supported with the present study. In another study, [10] observed the mean $( \pm \mathrm{SD})$ age of the subjects were $73.01 \pm 6.80$ years in osteoporosis group, $71.18 \pm 5.31$ years in osteopenia group and $70.11 \pm 5.52$ in control group. This result is consistent with our study. In this current study, it was observed that the mean $( \pm$ SD) T-score of femoral neck was $0.43 \pm 0.92$ in normal, $-1.79 \pm 0.41$ in osteopenia and $-3.01 \pm 0.66$ in osteoporosis, where differences were statistically significant. Similarly, Singh, Kumar and Lal (2015) study found that the mean $( \pm$ SD) T-score at femoral neck was $-1.74 \pm 0.6$ in cases and $1.15 \pm 1.2$ in controls, where $p$ value was less than 0.05 . Study by Jagtap, Ganu and Nagane (2011) found that the mean $( \pm \mathrm{SD}) \mathrm{T}$-score at femoral neck was $-3.233 \pm 0.752$ in osteoporotic group and $0.345 \pm 0.731$ in non-osteoporotic group, where pvalue was less than 0.05 . Above findings are consistent with the present study. In the present study, it was observed that the mean $( \pm \mathrm{SD})$ serum osteocalcin level significantly elevated in osteoporosis patients as compared to osteopenia and normal subjects, where the mean $( \pm)$ osteocalcin level was $13.88 \pm 1.11 \mathrm{ng} / \mathrm{mL}, 20.84 \pm 5.21 \mathrm{ng} / \mathrm{mL}$ and $24.32 \pm 5.24 \mathrm{ng} / \mathrm{mL}$ in normal subjects, osteopenia and osteoporosis respectively ( $p=0.001)$. Similarly, Singh, Kumar and Lal (2015) showed that the mean $( \pm \mathrm{SD})$ serum osteocalcin level significantly increase in osteoporosis patients $(22.03 \pm 5.16 \mathrm{ng} / \mathrm{mL})$ when compared to osteopenia $(19.25 \pm 5.09 \mathrm{ng} / \mathrm{mL})$ and control group $(16.20 \pm 2.77 \mathrm{ng} / \mathrm{mL})$, which was statistically significant. In another study, Kalaiselvi et al. (2013) found that the mean $( \pm \mathrm{SD})$ level of serum osteocalcin significantly raised in osteoporotic group $(16.16 \pm 4.5 \mathrm{ng} / \mathrm{mL})$ than non-osteoporotic group (11.26 $\pm 3.07 \mathrm{ng} / \mathrm{mL})$. Jagtap, Ganu and Nagane (2011) study observed that serum osteocalcin levels were significantly increased in osteoporotic $(25.184 \pm 4.974 \mathrm{ng} / \mathrm{mL})$ compared to control group $(11.467 \pm 3.183$ $\mathrm{ng} / \mathrm{mL}$ ). The findings are closely resembled with the present study. In this present study, the mean $( \pm \mathrm{SD})$ NLR was found $3.11 \pm 2.8$ in normal subjects, $4.49 \pm 2.04$ in osteopenia and $6.35 \pm 2.2$ in osteoporosis. The mean $( \pm$ SD) NLR was significantly increased in osteoporosis followed by osteopenia and normal subjects, where p-value was 0.010. [10] study observed that NLR of patients with osteoporosis $2.54 \pm 1.45$ were significantly higher than osteopenia $2.37 \pm 1.00$ and control group $2.18 \pm 0.85$. Similarly, Huang and Li (2016) study found the mean $( \pm$ SD) NLR was $2.12 \pm 0.89$ in normal group, $2.55 \pm 1.15$ in osteopenia group and $2.74 \pm 1.06$ in osteoporosis group. NLR was significantly elevated in osteoporosis group. This result is nearly consistent with) our study. Pearson's correlation test was done in order to assess the correlation of serum osteocalcin with T-score of BMD in osteoporosis patients. In this study it was observed that there is a significant negative Pearson's correlation was found between serum osteocalcin with T-score of BMD. Singh, Kumar and Lal (2015) studies found a significant inverse Pearson's correlation between the serum osteocalcin level and T-score of femoral neck BMD. In another study Kalaiselvi et al. (2013) showed a negative Pearson's correlation between serum osteocalcin level and femoral neck BMD, which correlates with the current study. In this study we also observed that there is a significant negative Pearson's correlation between NLR with T-score of femoral neck BMD [10]. shows, a significant negative Pearson's correlation between NLR with T-score of femoral neck BMD, which correlates with the current study. By using the ROC curve, we calculate the potential cut-off value to diagnosis of osteoporosis patients. An optimal cut-off value of serum osteocalcin was found $18.65 \mathrm{ng} / \mathrm{mL}$, with sensitivity $67.0 \%$ and specificity $70.0 \%$. Singh, Kumar and Lal (2015) found cut-off point of serum osteocalcin for the diagnosis of osteoporosis was $18.22 \mathrm{ng} / \mathrm{mL}$, with sensitivity $72.2 \%$ and specificity $70.5 \%$, which is comparable with the present study. Similarly, an optimum cut-off value of NLR for osteoporosis patient was found 4.54. This was determined by ROC curve to see the sensitivity and specificity of the test. In this study, sensitivity and specificity of NLR was found $72.0 \%$ and $75.0 \%$. This type of ROC curve was done for the first time. According to our study, it was demonstrated that a significant negative correlation between serum osteocalcin, NLR with BMD for the diagnosis of osteoporosis. Serum osteocalcin and NLR exhibited good diagnostic performance for the evaluation of osteoporosis.

\section{Conclusion}

Serum osteocalcin and NLR has significant negative correlation with Tscore of BMD. Because of high sensitivity and specificity, serum osteocalcin and NLR may be used to diagnosis of osteoporosis.

\section{References}

1. Ahmed, A.S., Haque, W.M.M.U., Uddin, K.N., Abrar, F.A., Afroz, F., Huque, H.F. and Afroze, S.R. (2018). Vitamin D and bone mineral density status among postmenopausal Bangladeshi women. IMC Journal of Medical Science, 12(2): 44-49.

2. Chaudhary, N.K., Timilsena, M.N., Sunuwar, D.R., Pradhan, P.M.S. and Sangroula, R.K., (2019). Association of lifestyle and food consumption with bone mineral density among people aged 50 years and above attending the hospitals of Kathmandu, Nepal. Journal of Osteoporosis. 1-6.

3. Forget, P., Khalifa, C., Defour, J.P., Latinne, D., Van Pel, M.C. and De Kock, M., (2017). What is the normal value of the neutrophil-to-lymphocyte ratio? BMC research notes, 10(1): 112. 
4. Häeussler, B., Gothe, H., Göl, D., Glaeske, G., Pientka, L. and Felsenberg, D., (2007). Epidemiology, treatment and costs of osteoporosis in Germany-the Bone EVA Study. Osteoporosis international, 18(1): 77-84.

5. Huang, C. and Li, S., (2016). Association of blood neutrophil lymphocyte ratio in the patients with postmenopausal osteoporosis. Pakistan journal of medical sciences, 32(3):762769.

6. Jagtap, V.R., Ganu, J.V. and Nagane, N.S., (2011). BMD and serum intact osteocalcin in postmenopausal osteoporosis women. Indian Journal of Clinical Biochemistry, 26(1): 70-73.

7. Johnell, O. and Kanis, J.A., (2004). An estimate of the worldwide prevalence, mortality and diasability associated with hip fracture. Osteoporos International. 15: 897-902.

8. Kaushal, N., Vohora, D., Jalali, R.K. and Jha, S., (2018). Prevalence of osteoporosis and osteopenia in an apparently healthy Indian population-a cross-sectional retrospective study. Osteoporosis and sarcopenia, 4(2): 53-60.
9. Kalaiselvi, V.S., Prabhu, K. and Mani Ramesh, V.V., (2013). The association of serum osteocalcin with the bone mineral density in post-menopausal women. Journal of clinical and diagnostic research: JCDR, 7(5): 814.

10. Öztürk, Z.A., Yesil, Y., Kuyumcu, M.E., Bilici, M., Öztürk, N., Yeşil, N.K., Özkaya, M., Kısacık, B., Kepekçi, Y. and Arığul, S., (2013). Inverse relationship between neutrophil lymphocyte ratio (NLR) and bone mineral density (BMD) in elderly people. Archives of gerontology and geriatrics, 57(1): 81-85.

11. Pagana, KD., Pagana, TJ., Pagana, TN., (2019). Mosby's Diagnostic \& Laboratory Test Reference. 14th ed., St. Louis, Mo.168.

12. Siddapur, P.R., Patil, A.B. and Borde, V.S., (2015). Comparison of bone mineral density, T-scores and serum zinc between diabetic and non-diabetic postmenopausal women with osteoporosis. Journal of laboratory physicians, 7(1): 43.

13. Singh, S., Kumar, D. and Lal, A.K., 2015. Serum osteocalcin as a diagnostic biomarker for primary osteoporosis in women. Journal of clinical and diagnostic research: JCDR. 9(8).

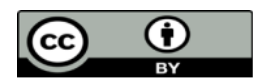

This work is licensed under Creative Commons Attribution 4.0 License

To Submit Your Article Click Here: Submit Manuscript

DOI: $10.31579 / 2768-0487 / 045$
Ready to submit your research? Choose Auctores and benefit from:

* fast, convenient online submission

* rigorous peer review by experienced research in your field

* rapid publication on acceptance

* authors retain copyrights

* unique DOI for all articles

* immediate, unrestricted online access

At Auctores, research is always in progress.

Learn more auctoresonline.org/journals/journal-of-clinical-andlaboratory-research 